\title{
Fatigue Crack Propagation Rate of High Strength Steel's Welded Joints
}

\author{
Hong-Tao $\mathrm{LI}^{1,2, a}$, Xu-Ding SONG ${ }^{1, b}$ \\ ${ }^{1}$ Ministry of Education Key Laboratory for Technology and Equipment of Highway Construction, \\ Chang'an University, Xi'an 710064, China \\ ${ }^{2}$ Department of Mechanical Engineering, Luoyang Institute of Science and Technology, Luoyang \\ 471023, China
}

ahtpsf@126.com, ${ }^{\text {b } 772371649 @ q q . c o m ~}$

Keywords: High Strength Low Alloy Steel, Fatigue Crack, $D a / d N-\Delta K$ Curve, Fatigue fracture, Microstructure.

\begin{abstract}
The high strength low alloy steel's (HG785D) welded joint was formed by strength match under MAG $(80 \% \mathrm{Ar}+20 \% \mathrm{CO} 2)$. The microstructure, micro-hardness and fatigue crack growth rate of the parent metal, weld and heat affected zone were tested and analyzed. The results show that the heat affected zone's hardness is highest and the parent metal's hardness is lowest; Different part of the butt joint's fatigue crack propagation rate is different at the same stress ratio, the heat affected zone's fatigue crack propagation rate is the fastest while the weld joint is the lowest. And through the analysis of fatigue fracture and the weld microstructure from the parent metal to the weld joint, the reason why different part's fatigue crack growth rate is different is that their metallographic microstructure is different. Chinese library classification: TG407.
\end{abstract}

\section{Introduction}

At present, China's major iron and steel company developed a series of high strength low alloy steel, Such as wisco's HG785D, HG980D, HG1080C, etc., Baosteel's BSM590, BS600MC, BS700MCK2, etc. High strength low alloy steel has the advantages such as high strength, low carbon content, etc., which has good weld ability and it can relieve structure total mass. It has been widely used in many engineering fields. Usually these steel structure were connected by welded and serving under cyclic loading, Because of the welded joint's mechanical properties is in homogeneity ${ }^{[1-2]}$, fatigue failure Often occurred during its service period and failure parts most occurred in welding joint, this seriously affected it's performance. Scholars at home and abroad carried out extensive research works on high strength low alloy steel welded joint fatigue performance, and their works mainly focused on the alloy elements, welding method and processing parameters, heat treatment, welding residual stress and fatigue performance. Bose-Filho W.W et al. analyzed the effect of alloying elements such an $\mathrm{Ti}, \mathrm{Ni}, \mathrm{Mo}, \mathrm{Cr}$ etc. to the microstructure and change rule after welded $^{[2]}$. Prasad K et al., studied the effect of submerged arc welding process parameters on the high strength low alloy steel welding joint microstructure, hardness and toughness ${ }^{[3]}$ etc. But so far, in our country, the research about high strength low alloy steel welding joint, mainly concentrated in the welding process, microstructure and the static mechanics characteristics. However the research about crack propagation properties and fatigue life prediction is relatively less. In this paper, HG785D high strength low alloy steel welding joint was the research object, its fatigue crack growth rate in parent metal and heat affected zone and weld joint was studied.

\section{Sample Preparation and Test Method}

\section{Sample Preparation}

Welding material's thickness is $20 \mathrm{~mm}$; its status is quenched and tempered. The main chemical composition and mechanical performance index are shown in table 1 and table 2, welding material is ER80 - G high strength wire.

The welding interface is $\mathrm{V}$-shaped groove, and it is $50^{\circ}$. Using the mixed gas welding $(80 \% \mathrm{Ar}+$ 
$20 \% \mathrm{CO} 2$ ), the electric arc voltage is $26 \mathrm{v}$, welding current is $120 \mathrm{~A}$, the welding speed is 340 $\mathrm{mm} / \mathrm{min}$, Two pieces of steel plate is multilayer flat welding, no preheating before welding and the welding type is the same intensity. The V groove and the standard SE (B) sample were made by Wire-cutting processing. The specific size and shape of welding joint were shown in figure 1 and figure 2 .

Tab.1 Chemical Composition of Test Steel $(\leq \mathrm{wt} \%)$

\begin{tabular}{llllllllll}
\hline Content of the element & $\mathrm{C}$ & $\mathrm{Si}$ & $\mathrm{Mn}$ & $\mathrm{P}$ & $\mathrm{S}$ & $\mathrm{Ni}$ & $\mathrm{Cr}$ & $\mathrm{Mo}$ & $\mathrm{B}$ \\
\hline Parent metal & 0.18 & 0.2 & 1.8 & 0.010 & 0.003 & - & 0.20 & 0.20 & 0.001 \\
\hline
\end{tabular}

Tab.2 Mechanical Properties of Test Steel

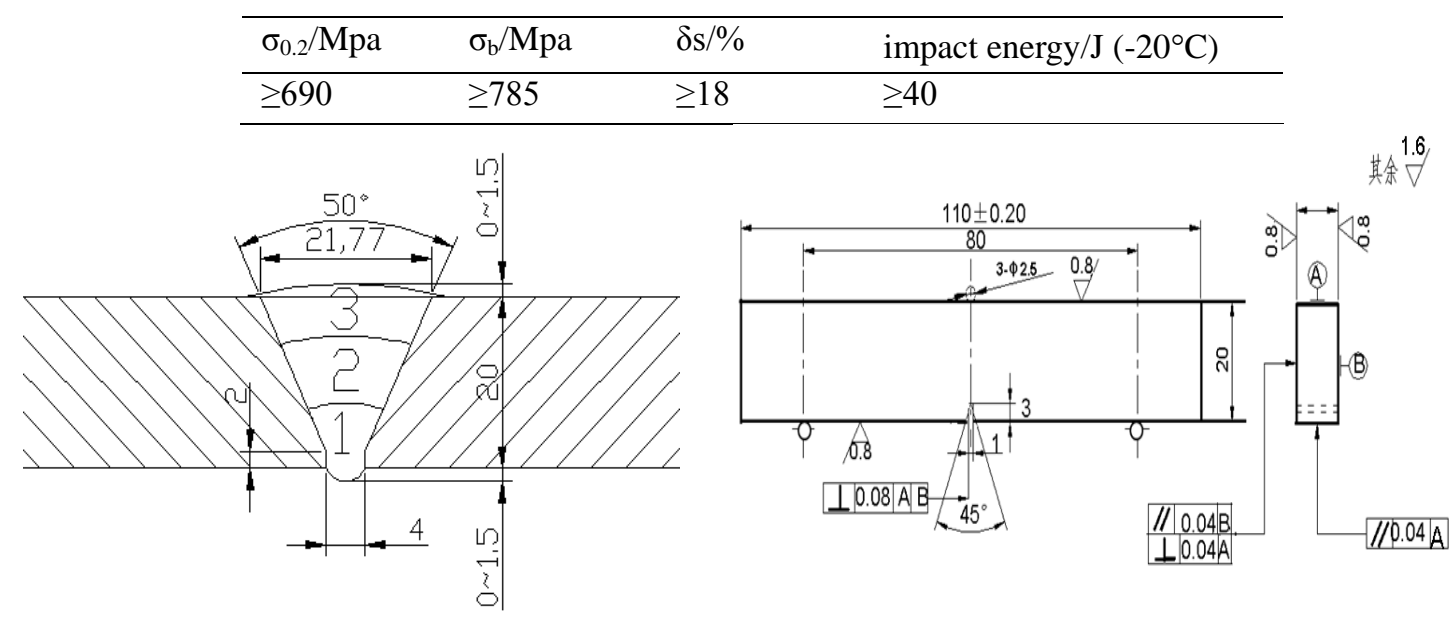

Fig.1 The Schematic Diagram of Weld

Fig.2 The Butt Joint of SE (B) Sample

\section{Test Method}

The microhardness near joint weld was tested according to the standard GB/T4342-1991 ${ }^{[4]}$, the specimen size was $25 \mathrm{~mm} \times 20 \mathrm{~mm} \times 10 \mathrm{~mm}$, and ensure the sample surface was parallel, flat and smooth. The measuring equipment was 402MVD type automatic turret digital micro vickers hardness tester, using four pyramid diamond indenter, the load was $1.96 \mathrm{~N}$, the hold time was $15 \mathrm{~s}$, measure the sample surface indentation diagonal length after unloading to determine the microhardness values. The measured sequence was from the weld center to the parent metal, the measurement point space was $3 \mathrm{~mm}$.

In order to analyze the fracture morphology, crack propagation characteristics, and ultimately transient breaking type, the fracture on the sample was analyzed by Hitachi S-4800 scanning electron microscope. In order to analyze the microstructure and composition of different regions, and analyzes its corresponding internal relation between the crack extension, metallographic analysis was taken about parent metal, weld joint and heat affected zone by the DMM - 480C metallographic microscope.

Fatigue test specimens were standard three point bending SE (B) sample which had unilateral gaps. Parent metal, heat affected zone and weld joint were made according to GB6398-2000 ${ }^{[5]}$ "metal fatigue crack propagation rate test method", and cut the gap by using the linear cutting. The sample's size and geometric shape was shown in figure 2.

Fatigue test was done on SDS500 electro-hydraulic servo testing machine, and the samples was clamped by FWDH8 standard three points bending clamping fixture. The test loads was sinusoidal alternating load, the maximum and minimum of cyclic load were $7.5 \mathrm{KN}$ and $1.5 \mathrm{KN}$, the stress ratio $\mathrm{R}$ was 0.2 , the loading frequency was $8 \mathrm{~Hz}$.

The parent metal, heat affected zone and weld fatigue crack propagation (a-N) curve was drawn by excel according to the test data of fatigue crack growth rate. 


\section{The Results and Discussion}

\section{The Results of Microhardness}

The figure 3 shows that the highest hardness of weld joint was $301.0 \mathrm{Hv}$, the lowest hardness is $256.7 \mathrm{Hv}$ and the average hardness was $277.04 \mathrm{Hv}$. The highest hardness of heat affected zone was $310.0 \mathrm{Hv}$, the lowest hardness was $277.4 \mathrm{Hv}$, and the average hardness was $295.89 \mathrm{Hv}$. The highest hardness of parent metal was $282.6 \mathrm{Hv}$, the lowest hardness was $237.6 \mathrm{Hv}$, and the average hardness was $258.77 \mathrm{Hv}$. As a result, the highest hardness was heat affected zone, the second is the weld zone and the parent metal is lowest.

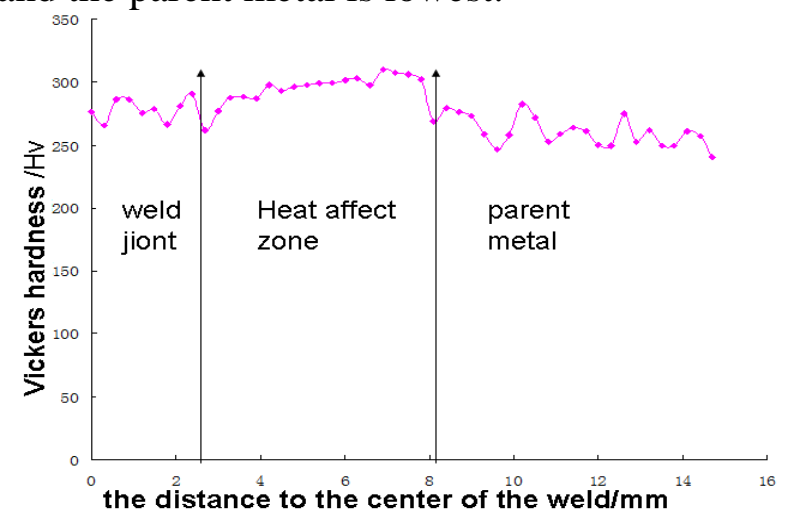

Fig.3 The Hardness Distribution of HG785D Steel Butt Joint

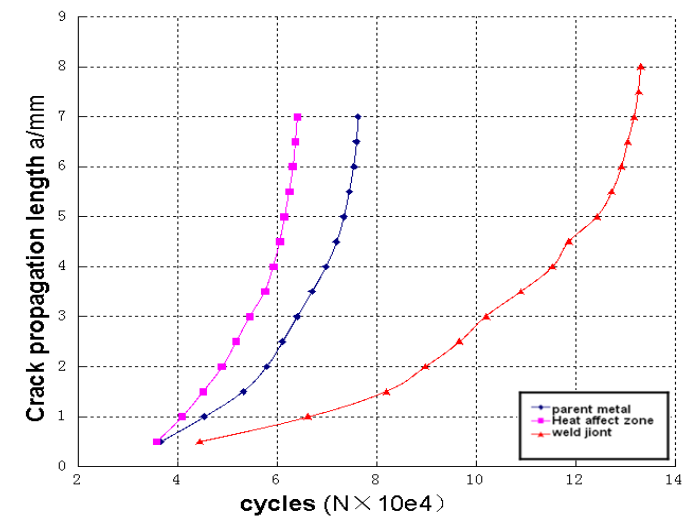

Fig.4 The (a-N) Curve of Fatigue Crack Growth in Different Positions

\section{Processed and Analyzed of Fatigue Test Data} 4.

The fatigue crack propagation (a-N) curve of weld joint's different location was shown in figure

On the basis of a - $\mathrm{N}$ curve, according to the seven points incremental polynomial method recommended by American society for testing and materials (ASTM), the fatigue crack propagation rate $(\mathrm{da} / \mathrm{dN})$ was calculated. The crack tip stress intensity factor corresponding to the $\mathrm{Da} / \mathrm{dN}$ was determined by the stress intensity factor formula according to three-point bend specimens SE (B). Related theory and the formula are as follows:

Seven points incremental polynomial method.

For the data point on the a-N curve I (exception of the former three points and the last three), and took the adjacent three points, before and after itself, the total points were seven, then the quadratic polynomial could be constructed:

$$
a_{i}=b_{0}+b_{1}\left(\frac{N_{j}-C_{1}}{C_{2}}\right)+b_{2}\left(\frac{N_{j}-C_{1}}{C_{2}}\right)^{2}
$$

$\mathrm{b}_{0} ; \mathrm{b}_{1}$ and $\mathrm{b}_{2}$ is regression coefficients based on the least square method, $a_{i}$ is the crack length in the name of the corresponding cycles $\mathrm{N}_{\mathrm{i}}$.

$$
C_{1}=\frac{1}{2}\left(N_{i+3}+N_{i-3}\right), C_{2}=\frac{1}{2}\left(N_{i+3}-N_{i-3}\right) .
$$

Derivative of (1), the fatigue crack propagation rate can be calculated under the corresponding $\mathrm{N}_{\mathrm{i}}$ :

$\left(\frac{d a}{d N}\right)_{a_{i}}=\frac{b_{1}}{C_{1}}+\frac{2 b_{2}\left(N_{i}-C_{1}\right)}{C_{2}^{2}}$ 


$$
\Delta K=\frac{\Delta P}{B \sqrt{W}}\left[\frac{6 \sqrt{\alpha}}{(1+\alpha)(1-\alpha)^{3 / 2}}\right] \times\left[1.99-\alpha(1-\alpha)\left(2.15-3.93 \alpha+2.7 \alpha^{2}\right)\right]
$$

$\alpha=a / W$, the results are effective when $0.3 \leq \alpha / W \leq 0.9$.

Using the method of seven points incremental polynomial method, based on the matlab programming tools, the fatigue crack growth rate da/dN of parent metal, heat affected zone and weld joint were calculated, and the corresponding $\Delta \mathrm{k}$ was calculated , and then, on the data obtained, according to Paris formula, use the least square method for linear regression analysis, get the $\mathrm{da} / \mathrm{dN}-\Delta \mathrm{K}$ curve (fig.5) and the crack propagation parameters of Paris formula (C and $\mathrm{m}$ ) (as shown in table 3).

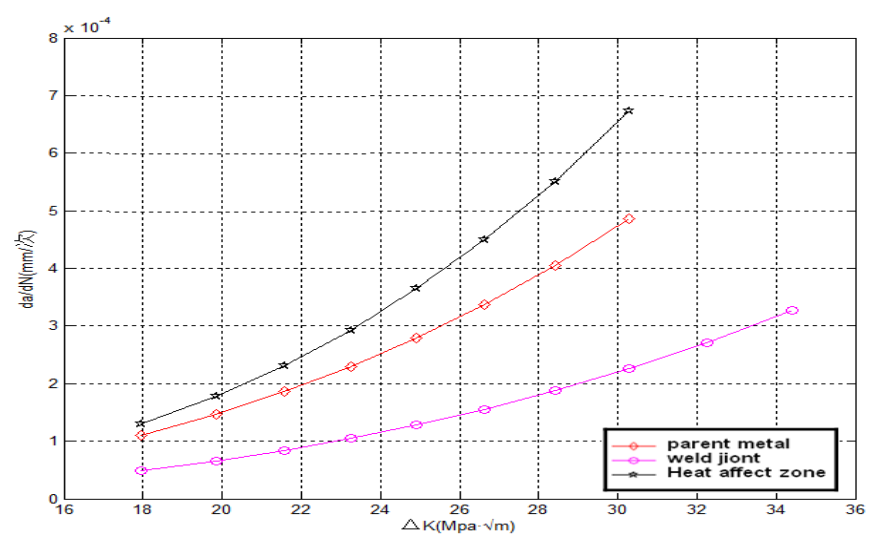

Fig.5 (Da/dN)- $\Delta$ K Curve of Welded Joint's Different Position

The figure 4 shown that Parent metal and heat affected zone sample's fatigue crack growth rate were rapid because their a-N curve were relatively steep. The number of stress cycles to different specimens was different, Parent metal specimen was approximately $7.5 \times 10^{4}$, heat affect zone specimen was approximately $6.5 \times 10^{4}$, and weld joint specimen was approximately $13.3 \times 10^{4}$. The total length of crack extension is different, Parent metal specimen was approximately $7 \mathrm{~mm}$, heat affect zone specimen was approximately $8 \mathrm{~mm}$, and weld joint specimen was approximately $7 \mathrm{~mm}$. Due to the influence of weld defects and weld residual stress concentration, so the weld joint's a-N curve is not smooth.

$\operatorname{lgC}$ is the fitting line intercept, with the decrease of the $\mathrm{C}$, the curve of crack growth rate went down, the crack growth rate was decreases. The table 3 shows that with the same stress ratio $R=0.2$, the value of material constant $C$ about different sample is different; the weld joint's $C$ is minimum while the heat affect zone's $\mathrm{C}$ is maximum. The heat affected zone's fatigue crack growth rate is the fastest while the weld joint is the lowest.

In conclusion that weld joint's fatigue load performance is best, the heat affected zone is worst.

Tab.3 The C, m Fitting Values of Paris Formula on Parent Metal, Heat Affected Zone and Weld Joint

\begin{tabular}{ccccc}
\hline Specimen & $\begin{array}{c}\text { Stress ratio } \\
\mathrm{R}\end{array}$ & $\mathrm{C}$ & $\mathrm{m}$ & correlation coefficient $\mathrm{r}$ \\
\hline parent metal & 0.2 & $2.160 \times 10-8$ & 2.9824 & 0.9908 \\
weld joint & 0.2 & $1.140 \times 10-8$ & 2.9016 & 0.9429 \\
heat affected zone & 0.2 & $1.348 \times 10-7$ & 2.4281 & 0.9703 \\
\hline
\end{tabular}

The corresponding regression equation of the Paris was shown below. 
The relationship between parent metal's fatigue crack growth rate da/dN and $\Delta \mathrm{K}$ :

$$
\mathrm{d} a / \mathrm{d} N=2.160 \times 10^{-8}(\Delta K)^{2.9824}(\mathrm{r}=0.9909)
$$

The relationship between weld joint's fatigue crack growth rate da/dN and $\Delta \mathrm{K}$ :

$$
\mathrm{d} a / \mathrm{d} N=1.140 \times 10^{-8}(\Delta K)^{2.9016}(\mathrm{r}=0.9429)
$$

The relationship between heat affect zone's fatigue crack growth rate da/dN and $\Delta \mathrm{K}$ :

$$
\mathrm{d} a / \mathrm{d} N=1.348 \times 10^{-7}(\Delta K)^{2.4281}(r=0.9703)
$$

\section{Fatigue Fracture Microstructure Analysis}

Fatigue crack extension is mainly fatigue stripe extensions (fig. 6), the width distribution of fatigue strip conforms to the trend of fatigue crack growth rate da/dN $\Delta$ K curve, different sample' s length of crack extension at one stress cycle period is different, the weld joint is minimum while the heat affect zone is maximum.

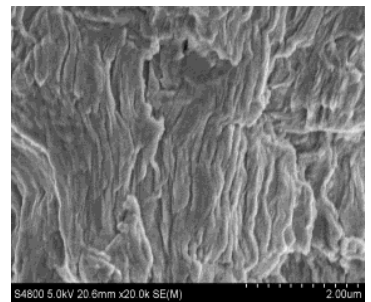

(a) Parent Metal

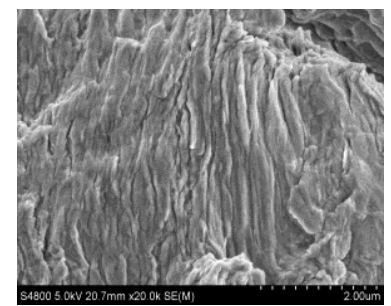

(b) Heat Affect Zone

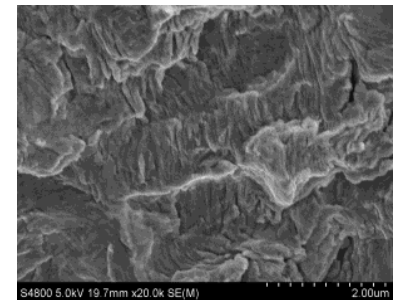

(c) Weld Joint

Fig.6 The Microstructure of Fatigue Crack Extension Fracture on Different Parts of Welding Joint

When the fatigue crack size reaches a critical size, crack was instability and expanded rapidly, samples were instantaneous fault. As shown in figure 7 is fracture morphology of fatigue crack instantaneous fracture.

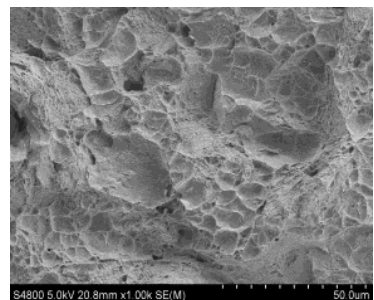

(a) Parent Metal

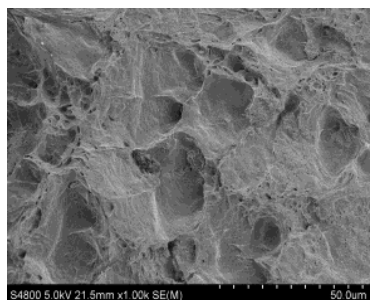

(b) Heat Affect Zone

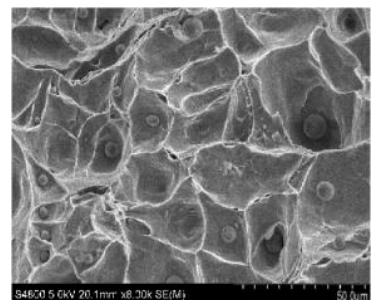

(c) Weld Joint

Fig.7 The Microstructure of Fatigue Crack Propagation Transient Fault Fracture on Different Sample

Figure 7 shows the transient fault zone of three samples had toughness nest. The toughness nests of weld joint were dense and fine; there were some second phase particles in it. The toughness nests of heat affect zone were less and there were obvious brittle fracture cleavage steps. The toughness nests of parent metal were between them. The number and depth of fatigue fracture toughness nests reflects the fatigue fracture toughness of the material. As a result, the weld specimen's fracture analysis results in line with fatigue crack growth rate da/dN $\Delta \mathrm{K}$ curve (fig.5).

\section{Microstructure}

The temperature near the weld joint rise and fall fast, the temperature field distribution is very uneven. The microstructure of different parts of the welding joint was shown in figure 8 . Weld joint (Fig.8a) is the mixture of "pearlite and ferrite". The farther from the bottom of molten pool, 
The proportion of ferritic was increase; the corresponding proportion of pearlite was reduced. The reason is that the welding process used $\mathrm{CO} 2$ as the shielding gas, which has strong oxidizability when it was decomposed under the action of high temperature arc, so that the alloy elements (including $\mathrm{C}$ elements) were oxidation loss. There was a fusion line between the intersection of weld zone and parent metal, and the microstructure changed obviously (Fig.8b). The microstructure translated to blocky ferrite, and the ferrite crystalline grain became bigger, it is overheated zone. The main reason for this phenomenon is that: first of all, the sample thickness is large, the heat input is high and the temperature is too high. Second, due to the high strength steel containing $1.8 \%$ $\mathrm{Mn}$, which promotes austenite and temperature gradient at the welding process, is very high; therefore, an overheating organization with bulky crystalline grain was formed. There were normalized zone and part of the phase change zone after overheating zone (Fig.8c) Microstructure of the parent metal sample (Fig.8d) was "ferrite and pearlite", which was small and uniform.

The photos of microstructure shows that this kind of high strength steel's organization were "ferrite and pearlite". When the crack extended from pearlite ferritic, due to the sudden increase of resistance, its speed came down. The size of crystalline grain influence the rate of crack propagation, the smaller the grain size, the higher the yield strength, the better the plasticity and the crack is not easy to generate. The crystalline grain in annealed zone grew up to a certain extent, so the crack propagation rate is faster than parent metal. Due to the organization of weld joint is very small, the crack initiation is difficult, the crack propagation rate is slow.

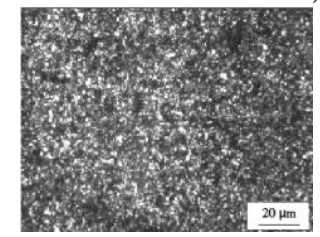

(a) Weld Joint

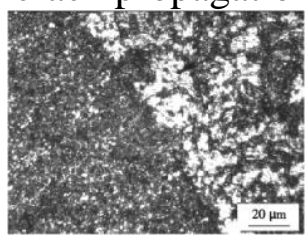

(b) Fusion Zone

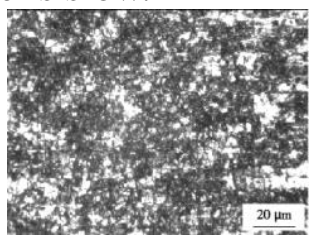

(c) Recrystallization Zone

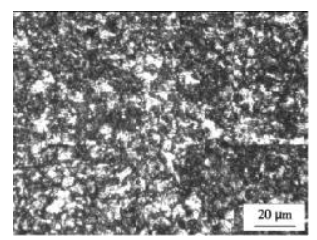

(d) Parent Metal

Fig. 8 Microstructure of Welded Joints in Different Parts $\times 500$

\section{Conclusion}

(1) The low alloy steel HG785D weld joint's hardness is $256.7 \sim 301.1 \mathrm{HV}$, the average hardness was $277.04 \mathrm{Hv}$. The heat affect zone's hardness is $237.6 \sim 282.6 \mathrm{HV}$, the average hardness was $295.89 \mathrm{Hv}$. The parent metal's hardness is $277.4 \sim 310.0$, the average hardness was $258.77 \mathrm{Hv}$. The maximum hardness is in the heat affected zone, because its grains grow bigger, the brittleness is increased.

(2) The a-N curve and fatigue crack growth rate da/dN- $\Delta \mathrm{K}$ curve were got experiments. The linear correlation coefficient of experimental data is higher.

(3) Different part of the butt joint's fatigue crack propagation rate is different at the same stress ratio; the heat affected zone's fatigue crack propagation rate is the fastest while the weld joint is the lowest.

(4) When the low alloy steel HG785D was welded at conventional welding conditions, the fatigue crack growth resistance is different in different part of joint, the weld joint is best, the heat affected zone is worst.

\section{Reference}

[1] Zhang Chunguo, Study on fatigue crack growth performance of welded high-strength steel with a bi-metal weld seam [D]. Chang'an University, Xi'an, China, 2013.

[2] Bose-Filho W.W., Carvalho A.l.m. Effect of alloying elements on the microstructure and inclusion formation in HSLA multipass welds [J]. Materials Characterization, 2007, 58:29-39.

[3] Prasad k., Dwivedi D.K., Some investigations on microstructure and mechanical properties of submerged arc welded HSLA steel joints [J]. International Journal of Advanced Manufacturing 
Technology, 2008, 36:475-483.

[4] GB/T4342-1991 Metal microhardness testing method [S]. Beijing: China Standards Press, 1991.

[5] GB6398-2000 Metal material fatigue crack growth rate test method[S]. Beijing: China Standards Press, 2000.

[6] Zhang Chunguo, Stefan van der Vyer, Hu Xiaozhi.Fatigue crack growth behavior in weld-repaired high strength low alloy steel [J]. Engineering Fracture Mechanics, 2011, 78:1862-1875.

[7] Zhang Chunguo, Song Xuding, Lu Pengmin, Xiao Hu.Effect of microstructure on mechanical properties in weld-repaired high strength low alloy steel [J]. Material and Design, 2012, $36: 233-242$. 